УДК 334.726

$10.17213 / 2075-2067-2021-3-225-229$

\title{
МЕХАНИЗМЫ И МОДЕЛИ, ИСПОЛЬЗУЕМЫЕ В РАЗВИТИИ СОВМЕСТНОГО ПРЕДПРИНИМАТЕЛЬСТВА В РЕГИОНАХ
}

\section{(C) 2021 г. М. П. Тертышникова}

\section{Ростовский государственный экономический университет (РИНХ), 2. Ростов-на-Дону, Россия}

Целью исследования является изучение развития совместного предпринимательства как экономического явления в Российской Федерации в целом и в частности в регионах в условиях трансформачионных прочессов на фоне изменяющейся экономической обстановки и экономических санкиий.

Методологической основой исследования являются научные разработки, теоретические и практические исследования отечественных и зарубежных авторов экономических отношений, которые содержатся в работах по изучению проблем совместного предпринимательства, а также материаль Федеральной службы государственной статистики по развитию регионов.

Результаты исследования. В статье рассматриваются механизмы и модели, используемые в развитии совместного предпринимательства в регионах России с учетом изменяющихся экономических условий ужесточения санкций различных стран, приведших к резкому снижению количества компаний рассматриваемого вида. Авторами статьи были проработаны статистические данные социально-экономических показателей компаний в виде совместного предпринимательства за пять лет, а также результаты экономических исследований российских ученых в этой области. Полученные результаты наглядно показывают, что создавшаяся экономическая обстановка в нашей стране приводит к ухудшению сотрудничества между российскими и иностранными компаниями.

Перспективу исследования представляет дальнейший экономический анализ развития совместного предпринимательства в регионах России.

Ключевые слова: совместное предпринимательство; иностранный капитал; валовый внутренний продукт; ВВП; экономические санкции.

\section{MECHANISMS AND MODELS USED IN THE DEVELOPMENT OF JOINT ENTREPRENEURSHIP IN THE REGIONS}

\section{(C) 2021 M. P. Tertyshnikova}

\section{Rostov State University of Economics (RSUE), Rostov-on-Don, Russia}

The purpose of the study is to study the development of joint entrepreneurship as an economic phenomenon in the Russian Federation as a whole and in particular in the regions in the context of transformational processes against the background of the changing economic situation and economic sanctions.

The methodological basis of the research is the scientific developments, theoretical and practical studies of domestic and foreign authors of economic relations, which are contained in 
the works on the study of the problems of joint entrepreneurship, as well as the materials of the Federal State Statistics Service for the Development of Regions.

The results of the study. The article examines the mechanisms and models used in the development of joint entrepreneurship in the regions of Russia, taking into account the changing economic conditions of the tightening of sanctions of various countries, which led to a sharp decrease in the number of companies of this type. The authors of the article studied the statistical data of socio-economic indicators of companies in the form of joint ventures for five years, as well as the results of economic research by Russian scientists in this field. The results clearly show that the current economic situation in our country leads to a deterioration in cooperation between Russian and foreign companies.

The perspective of the study is the further economic analysis of the development of joint entrepreneurship in the regions of Russia.

Key words: joint venture; foreign capital; gross domestic product; GDP; economic sanctions.

Введение. Актуальность проведения экономических исследований в области развития совместного предпринимательства в регионах Российской Федерации является особо значимой и перспективной по многим факторам, относящимся к худшению экономической ситуации из-за затянувшегося кризиса, связанного с внешнеэкономической политикой страны и санкциями других государств. Развитие совместного предпринимательства базируется прежде всего на взаимовыгодном интересе партнеров, преследующих каждый свой интерес в создании такой компании. Теоретические основы образования этих компаний изучаются различными экономическими институтами, что подтверждается проведением многочисленных исследований, сложившимися определенными традициями и школами.

Теоретические и практические вопросы совершенствования методов оценки, анализа, прогнозирования, повышения конкурентоспособности компании, принятия эффективных управленческих решений по выбору оптимальной стратегии развития в условиях нестабильной экономической обстановки посвящены исследования ряда зарубежных и отечественных ученых, таких как М. Портер, Ж.-Ж. Ламбен, И. Ансофф, Г. Саймон, И. Астахов, О. Виханский, Е. Горбашко, П. Завьялов, Н. Моисеев, А. Петров, И. Фаминский, Р. Фатхутдинов и др. Отдельные вопросы управления конкурентоспособностью совместных предприятий рассматриваются в работах по региональному развитию, экономической безопасности, инвестиционной привлекательности, инновационной активности, формированию экономической и промышленной политики и т.д. (Л. Абалкин, С. Валдайцев, В. Воротилов, С. Глазьев, Б. Гринчель, А. Карлик, И.В. Липсиц, Б. Мильнер, А. Румянцев, И. Сигов, Р.М. Тихонов, Р.А. Фатхутдинов, Р. Шнипер, Ю. Яковец и др.). Ими внесен значительный вклад в разработку основополагающих проблем принятия оптимального управленческого решения и деятельности совместных предприятий.

Анализ научной литературы показывает, что изучение проблемы успешного развития и стабильного функционирования совместного предпринимательства в регионах России в настоящее время активно изучается и по этой тематике публикуется большое количество научных статей как в России, так и за рубежом.

Цель и предмет исследования. Целью исследования в настоящей статье является анализ механизмов и моделей, используемых в развитии совместного предпринимательства в российских регионах, проведение анализа статистических данных влияния введения экономических санкций на реальное положение компаний с рассматриваемой формой собственности.

Методология исследования. Методологической основой исследования являются научные разработки, теоретические и практические предложения, представленные отечес- 
твенными и зарубежными учеными в области экономических наук, которые содержатся в работах по изучению развития совместного предпринимательства в зависимости от цели создания и выбора организационной формы компании.

Научные результаты исследований. Совместное предпринимательство (СП) это самостоятельная экономическая единица, созданная двумя или несколькими, как юридическими, так и физическими лицами, одно из которых является представителем другого государства. При определении цели организации такого вида компании используются следующие модели развития бизнеса [6]:

- повышение эффективности бизнеса;

- новые технологии, патенты, лицензии для расширения ассортимента и увеличения рынка сбыта продукции;

- развитие действующей компании за счет привлечения дополнительных инвестиций;

- уменьшение риска при производстве новых видов продукции.

В зависимости от выбранной модели организации совместного предпринимательства необходимо определиться с механизмом его развития. Здесь ключевыми моментами будут такие аспекты, как организационно-правовая форма СП, доля иностранного капитала в уставном фонде компании, ее организационная структура и др. [7].

Особенностью экономической деятельности совместного предпринимательства на территории Российской Федерации является развитие внешнеэкономических связей, что способствует развитию инновационных технологий в различных сферах бизнеса, привлечение иностранных инвестиций и научно-технического опыта, повышение эффективности производства за счет международного разделения труда. Иностранным бизнесменам интересны инвестиции в России, так как это открывает им новые рынки сбыта своей продукции, сравнительно низкооплачиваемая рабочая сила, большое количество природных ресурсов.

Проанализируем основные социально-экономические показатели рынка труда за 2015-2019 гг. (табл. 1). Все показатели за рассматриваемый период имеют положительную тенденцию, что говорит о стабилизации экономики и рынка труда, несмотря на сложную обстановку внешней политики и введение санкций против России. То же можно сказать и о ВВП страны, представленном в табл. 2.

Данные предыдущих таблиц говорят о стабильном улучшении экономической обстановки в стране, что должно было бы привлечь иностранных инвесторов и способствовать увеличению количества компаний, образованных на базе совместного предпринимательства. Рассмотрим число организаций с долей иностранной собственности за анализируемый период и их оборот (табл. 3, 4) [1-5].

Резкое снижение оборота СП в 2019 году произошло из-за сокращения положительного сальдо торгового баланса, которое было вызвано снижением стоимостных показателей экспорта топливно-энергетических то-

Показатели рынка труда

Таблица 1

\begin{tabular}{|l|c|c|c|c|c|}
\hline \multicolumn{1}{|c|}{ Показатели } & 2015 & 2016 & 2017 & 2018 & 2019 \\
\hline Уровень безработицы, \% & 6,4 & 5,3 & 5,1 & 4,8 & 4,6 \\
\hline Коэффициент напряженности, чел. на 100 вакансий & 92 & 87 & 60 & 54 & 50 \\
\hline Численность занятых, тыс. чел. & 72322 & 72755 & 72335 & 72612 & 72669 \\
\hline
\end{tabular}

Таблица 2

Валовый внутренний продукт

\begin{tabular}{|c|c|c|c|c|c|}
\hline Показатели & 2015 & 2016 & 2017 & 2018 & 2019 \\
\hline ВВП, млрд. руб. & 83087,30 & 85616,10 & 91843,20 & 103861,70 & 109241,50 \\
\hline
\end{tabular}


Таблица 3

Число предприятий

и организаций с долей иностранной собственности по округам

\begin{tabular}{|l|c|c|c|}
\hline \multicolumn{1}{|c|}{ Регион } & 2017 & 2018 & 2019 \\
\hline Всего & 45286 & 39805 & 35111 \\
\hline ЦФО & 25609 & 21901 & 19014 \\
\hline СЗФО & 7543 & 6629 & 5894 \\
\hline ЮФО & 3790 & 3559 & 3127 \\
\hline СКФО & 468 & 421 & 406 \\
\hline ПФО & 2960 & 2787 & 2436 \\
\hline УФО & 1443 & 1270 & 1188 \\
\hline СФО & 2102 & 1667 & 1532 \\
\hline ДВ & 1371 & 1571 & 1514 \\
\hline
\end{tabular}

варов на фоне ухудшения мировой ценовой конъюнктуры.

Самыми привлекательными регионами для СП на протяжении всего рассматриваемого периода остаются Центральный и Северо-Западный федеральные округа. Чаще всего такой бизнес вкладывает средства в компании, которые занимаются финансовой и страховой деятельностью, в сферу торговли, в сектор промышленности и высоких технологий, а также в недвижимость.

Заключение. Таким образом, проанализировав статистические данные количества и годового оборота совместных предприятий, можно сделать вывод, что резкое их сокращение в 2019 году произошло из-за введения санкций США и некоторых европейских стран на определенные виды инвестирования на территории РФ, а также из-за снижения стоимостных показателей топливно-энергетических товаров. Однако, Россия остается страной, привлекательной для иностранных инвесторов и создания новых совместных предприятий как в области добычи полезных ископаемых, приборо- и машиностроения, так и в других областях.

\section{Литература}

1. Россия в цифрах [Электронный ресурс] // Федеральная служба государствен-
Годовой оборот предприятий

Таблица 4

и организаций с долей

иностранной собственности по округам, млрд. руб.

\begin{tabular}{|l|c|c|c|}
\hline \multicolumn{1}{|c|}{ Регион } & 2017 & 2018 & 2019 \\
\hline Всего & 32320,4 & 36676,7 & 16578,9 \\
\hline ЦФО & 19614,4 & 22211,4 & 11577,3 \\
\hline СЗФО & 3532,3 & 3872,8 & 897,5 \\
\hline ЮФО & 1062,5 & 1163,8 & 297,5 \\
\hline СКФО & 93,7 & 86,9 & 70,1 \\
\hline ПФО & 2438 & 2955,5 & 2144 \\
\hline УФО & 2931,6 & 2914,8 & 705,6 \\
\hline СФО & 1541,6 & 1936 & 439,7 \\
\hline ДВ & 1106,1 & 1535,5 & 441 \\
\hline
\end{tabular}

ной статистики (Росстат). Официальное издание. - 2020. - Режим доступа: https:// rosstat.gov.ru/storage/mediabank/fimgAF33/ Region Pokaz 2020.pdf.

2. Россия в цифрах [Электронный ресурс] // Федеральная служба государственной статистики (Росстат). Официальное издание. - 2019. - Режим доступа: https:// rosstat.gov.ru/storage/mediabank/1dJJCOvT/ Region Pokaz 2019.pdf.

3. Регионы России. Социально-экономические показатели [Электронный ресурс] // Федеральная служба государственной статистики (Росстат). Официальное издание. 2018. - Режим доступа: https://rosstat.gov.ru/ storage/mediabank/Reg-pok18.pdf.

4. Регионы России. Социально-экономические показатели [Электронный ресурс]// Федеральная служба государственной статистики (Росстат). Официальное издание. 2017. - Режим доступа: peg-pok17.pdf (rosstat.gov.ru).

5. Багратуни К. Ю. и др. Иостранные инвестиции и совместное предпринимательство. - М., Изд-во «Русайн», 2016. — 148 с.

6. Борисенко В.В. Совместное предпринимательство / Бухгалтерский учет. 2017. - №6. - C. 16-22.

7. Тертышиникова М.П. Развитие бизнес-структур в экономике совместного предпринимательства / Наука и образование: хозяйство и экономика; предпринимательство; 
право и управление. - 2017. — №4 (83). C. 26-28.

\section{References}

1. Rossija $\mathrm{v}$ cifrah [Russia in numbers] [Jelektronnyj resurs] // Federal'naja sluzhba gosudarstvennoj statistiki (Rosstat). Oficial'noe izdanie [Federal State Statistics Service (Rosstat). Official publication]. - 2020. — URL: https://rosstat.gov.ru/storage/mediabank/fimgAF33/Region_Pokaz_2020.pdf.

2. Rossija $\mathrm{v}$ cifrah [Russia in numbers] [Jelektronnyj resurs] // Federal'naja sluzhba gosudarstvennoj statistiki (Rosstat). Oficial'noe izdanie [Federal State Statistics Service (Rosstat). Official publication]. — 2019. — URL: https:// rosstat.gov.ru/storage/mediabank/1dJJCOvT/ Region_Pokaz_2019.pdf.

3. Regiony Rossii. Social'no-jekonomicheskie pokazateli [Regions of Russia. Socioeconomic indicators] [Jelektronnyj resurs] // Federal'naja sluzhba gosudarstvennoj statistiki (Rosstat). Oficial'noe izdanie [Federal State Statistics Service (Rosstat). Official publication]. -
2018. — URL: https://rosstat.gov.ru/storage/mediabank/Reg-pok18.pdf.

4. Regiony Rossii. Social'no-jekonomicheskie pokazateli [Regions of Russia. Socioeconomic indicators] [Jelektronnyj resurs] // Federal'naja sluzhba gosudarstvennoj statistiki (Rosstat). Oficial'noe izdanie [Federal State Statistics Service (Rosstat). Official publication]. 2017. — URL: peg-pok17.pdf (rosstat.gov.ru).

5. Bagratuni K. Ju. et al. Iostrannye investicii i sovmestnoe predprinimatel'stvo [Foreign Investments and joint entrepreneurship]. Moscow, Izd-vo «Rusajn», 2016. — 148 p.

6. Borisenko V.V. Sovmestnoe predprinimatel'stvo [Joint entrepreneurship] / Buhgalterskij uchet [Accounting]. - 2017. — №6. - Pp. 16-22.

7. Tertyshnikova M.P. Razvitie biznes-struktur $\mathrm{v}$ jekonomike sovmestnogo predprinimatel'stva [Development of business structures in the economy of joint entrepreneurship]/Nauka i obrazovanie: hozjajstvo i jekonomika; predprinimatel'stvo; pravo i upravlenie [Science and education: economy and economy; entrepreneurship; law and management]. — 2017. — №4(83). — Pp. 26-28.

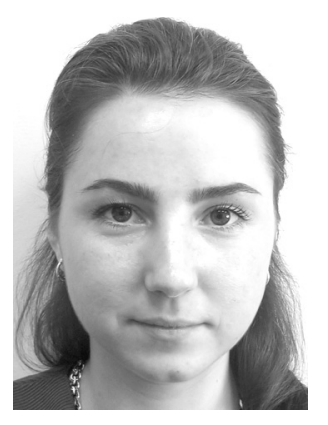

Тертышникова Маргарита Павловна - аспирант кафедры «Экономика региона, отраслей и предприятий» Ростовского государственного экономического университета (РИНХ).

Tertyshnikova Margarita Pavlovna - Post-graduate student of the Department «Economy of the region, Industries and Enterprises», Rostov State University of Economics (RSUE).

344002, г. Ростов-на-Дону, ул. Большая Садовая, 69 69 Bolshaya Sadovaya st., 344002, Rostov-on-Don, Russia

E-mail: mpsaratsyn@gmail.com 